\title{
Abnormal Mineral Formation in Aluminate Cement Stone
}

\author{
I. Zhernovsky ${ }^{(\bowtie)}$, V. Strokova, V. Nelyubova, Yu. Ogurtsova, \\ and M. Rykunova \\ Belgorod State Technological University named after V.G. Shukhov, \\ Belgorod, Russia \\ zhernovsky.igor@mail.ru, zhernovskiy.iv@bstu.ru
}

\begin{abstract}
The paper describes the results of the study on the correlation between the strength properties and the concentration of calcium aluminate hydrates during long hardening of aluminate cement in aqueous medium. It shows the abnormal nature of hydrate mineral formation in the system of hardening aluminate cement.
\end{abstract}

Keywords: Aluminate cement $\cdot$ Calcium aluminate hydrates

\section{Introduction}

The properties of any composite materials directly depend on the characteristics of their base matrix. This also fully applies to composites based on binding agents with various composition, which quality indicators are set as a result of system hardening (Strokova et al. 2015; Kozhukhova et al. 2016; Nelyubova et al. 2017; Dmitrieva et al. 2018; Shulpekov et al. 2018). In this regard the study of phase formation in such systems seems quite relevant.

Construction materials based on aluminate cements have different properties than those based on portland cement. In particular, they are characterized by a high thermal stability and resistance to acid corrosion (Kuznetsova 1986; Kuznetsova et al. 1989).

The calcium aluminate hydrates, which are formed through hardening of aluminate cement, represent the following phases: $\mathrm{CAH}_{10}, \mathrm{C}_{2} \mathrm{AH}_{8}, \mathrm{C}_{3} \mathrm{AH}_{6}, \mathrm{AH}_{3}$ (gibbsite). From this point onward the 'cement' notation in formulas of chemical compounds will be used $\left(\mathrm{C}-\mathrm{CaO}, \mathrm{A}-\mathrm{Al}_{2} \mathrm{O}_{3}, \mathrm{H}-\mathrm{OH}\right)$.

The hydrate mineral formation in aluminate cements is characterized by the dependence of $\mathrm{C}-\mathrm{A}-\mathrm{H}$ phases on temperature. At a temperature below $15^{\circ} \mathrm{C}$ the main reaction-active $\mathrm{CA}$ phase is hydrated according to the following scheme: $\mathrm{CA}+10 \mathrm{H} \rightarrow$ $\mathrm{CAH}_{10}$. At room temperature the $\mathrm{C}-\mathrm{A}-\mathrm{H}$ is formed according to the following scheme: $2 \mathrm{CA}+11 \mathrm{H} \rightarrow \mathrm{C}_{2} \mathrm{AH}_{8}+\mathrm{AH}_{3}$. At higher temperatures (above $28{ }^{\circ} \mathrm{C}$ ) the metastable hydrates $\mathrm{CAH}_{10}$ and $\mathrm{C}_{2} \mathrm{AH}_{8}$ will transform into stable hydrate $\mathrm{C}_{3} \mathrm{AH}_{6}$ according to the following equations: $3 \mathrm{CAH}_{10} \rightarrow \mathrm{C}_{3} \mathrm{AH}_{6}+2 \mathrm{AH}_{3}+18 \mathrm{H}$ and $3 \mathrm{C}_{2} \mathrm{AH}_{8} \rightarrow 2 \mathrm{C}_{3} \mathrm{AH}_{6}+$ $\mathrm{AH}_{3}+9 \mathrm{H}$ (Rashid et al. 1994).

Thus, according to insights into hydration of aluminate cements, the hydrate phases during long hydration shall be presented as follows: $\mathrm{C}_{3} \mathrm{AH}_{6}+\mathrm{AH}_{3}$. 
The paper provides the results of hydration hardening of aluminate cement with long-term exposure to aqueous medium, which contradict the above ideas.

\section{Materials and Methods}

The aluminate cement GTS-50 produced by JSC Pashiysky Cement and Metallurgical Plant (Perm Region, Russian Federation) was used in the study as a binding agent. Cubes with a $2 \mathrm{~cm}$ side are formed from cement paste (water-cement ratio equal 0.3 ). After hardening on the $1^{\text {st }}$ day the samples were taken from a mold and placed into the desiccator with $100 \%$ air humidity. After 28 days the samples were dried in a drying cabinet at $80{ }^{\circ} \mathrm{C}$ and placed in water, from which they were taken for further study in 1 , 2, 3 and 4 months.

The study methods included the compression strength test on PGM-100 MG4 press (average against three measurements) and the quantitative full-scale XRF to define potential changes in mineral composition.

The diffraction spectra of samples were obtained via the ARL X'TRA diffractometer $\left(\lambda_{\mathrm{Cu}}\right)$ in the range of diffraction angles $2 \theta^{\circ}=4-64$, step angle $-0.02^{\circ}$. The diffraction spectra were smoothened prior to treatment.

The quantitative full-scale XRF was carried out via the DDM v.1.95e software for a difference curve derivative (Solovyov 2004).

\section{Results and Discussion}

According to XRF, the mineral composition of GTS-50 cement is presented by the following crystal formations (wt.\%): $\mathrm{CA}$ (28.3), $\mathrm{CA}_{2}$ (9.2), $\mathrm{C}_{12} \mathrm{~A}_{7}$ (1.4), akermanitegelenite (15.6), $\beta-\mathrm{C}_{2} \mathrm{~S}$ (10.0), $\alpha^{\prime}{ }_{\mathrm{H}}-\mathrm{C}_{2} \mathrm{~S}$ (10.2), wollastonite $2 \mathrm{M}$ (7.6), dolomite (10.6), perovskite (7.2).

$\mathrm{X}$-ray diagnostics of mineral phases in hydrated samples of aluminate cement indicated the presence of $\mathrm{CAH}_{10}, \mathrm{C}_{2} \mathrm{AH}_{8}, \mathrm{C}_{3} \mathrm{AH}_{6}, \mathrm{AH}_{3}$, akermanite-gelenite, $\beta-\mathrm{C}_{2} \mathrm{~S}$, $\alpha^{\prime}{ }_{\mathrm{H}^{-}} \mathrm{C}_{2} \mathrm{~S}$, wollastonite $2 \mathrm{M}$, dolomite and perovskite.

Due to lack of $\mathrm{C}_{2} \mathrm{AH}_{8}$ structural model, the quantitative XRF was combined with the approach suggested by Cuberos et al. (2009).

As data show (Table 1), for nearly 5 months (28 days in damp atmosphere and 4 months in water) $\mathrm{CAH}_{10}$ remains the main hydrate phase. The reduction of $\mathrm{CAH}_{10}$ concentration on the $2^{\text {nd }}$ month in water, which correlates well with the increase of crystal gibbsite $\left(\mathrm{AH}_{3}\right)$, does not lead to the similar increase of $\mathrm{C}_{3} \mathrm{AH}_{6}$. Most likely it is caused by the formation of $\mathrm{C}_{3} \mathrm{AH}_{6}$ in its cryptocrystalline state.

The abnormal nature of hydrate mineral formation includes the increase of $\mathrm{CAH}_{10}$ metastable hydrate concentration starting from the $3^{\text {rd }}$ month. At the same time the temporal change of $\mathrm{C}_{3} \mathrm{AH}_{6}$ concentration coincides well with the change of compression strength of the studied samples (Fig. 1). 
Table 1. Concentration of hydrate phases (wt. \%)

\begin{tabular}{l|r|l|l|r}
\hline Time in aqueous medium, months & $\mathrm{CAH}_{10}$ & $\mathrm{C}_{2} \mathrm{AH}_{8}$ & $\mathrm{C}_{3} \mathrm{AH}_{6}$ & $\mathrm{AH}_{3}$ \\
\hline 0 & 18.8 & 3.5 & 3.1 & 2.0 \\
\hline 1 & 26.5 & 4.4 & 8.2 & 5.9 \\
\hline 2 & 9.0 & 2.1 & 6.8 & 25.1 \\
\hline 3 & 33.5 & 3.5 & 4.7 & 6.3 \\
\hline 4 & 37.2 & 5.8 & 5.6 & 3.0 \\
\hline
\end{tabular}

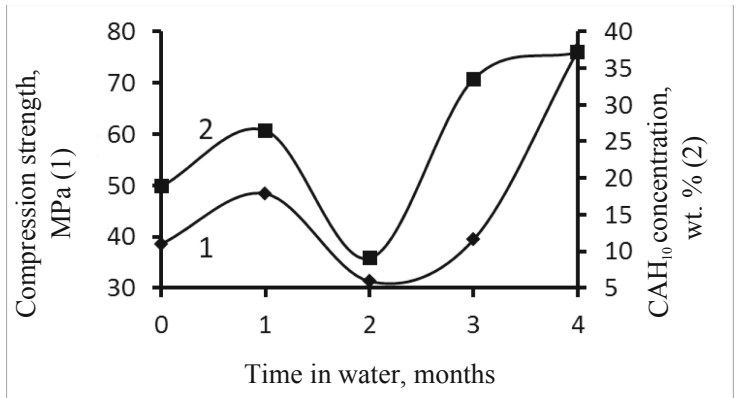

Fig. 1. Compression strength of aluminate cement stone and $\mathrm{CAH}_{10}$ concentration depending on time

\section{Conclusions}

The paper describes the results of the study on the correlation between the strength properties and the concentration of calcium aluminate hydrates during long hardening of aluminate cement in aqueous medium. At present it is impossible to give unambiguous interpretation of the observed abnormal compositional changes of hydrate phases of hydrated aluminate cement during long hardening.

Acknowledgements. The study is carried out in the framework of the State Task of the RF Ministry of Education and Science No. 7.872.2017/4.6. Development of principles for the design of ecologically positive composite materials with prolonged bioresistance 2017-2019.

\section{References}

Cuberos AJM, De la Torre ÁG, Martín-Sedeño MC, Moreno-Real L, Merlini M, Ornez LM, Aranda MAG (2009) Phase development in conventional and active belite cement pastes by Rietveld analysis and chemical constraints. Cem Concr Res 39:833-842

Dmitrieva TV, Strokova VV, Bezrodnykh AA (2018) Influence of the genetic features of soils on the properties of soil-concretes on their basis. Constr Mater Prod 1(1):69-77 
Kozhukhova NI, Chizhov RV, Zhernovsky IV, Strokova VV (2016) Structure formation of geopolymer perlite binder vs. type of alkali activating agent. ARPN J Eng Appl Sci 11 (20):12275-12281

Kuznetsova TV (1986) Aluminate and sulfo-aluminate cements, Moscow

Kuznetsova TV, Kudryashov IV, Timashev VV (1989) Physical chemistry of binding materials, Moscow

Nelyubova V, Pavlenko N, Netsvet D (2015) Cellular composites with ambient and autoclaved type of hardening with application of nanostructured binder. In: IOP Conference series: materials science and engineering, vol 96, no 1, p 012010

Nelyubova VV, Strokova VV, Sumin AV, Jernovskiy IV (2017) The structure formation of the cellular concrete with nanostructured modifier. Key Eng Mater 729:99-103

Rashid S, Barnes P, Bensted J, Turrillas X (1994) Conversion of calcium aluminate cement hydrates re-examined with synchrotron energy-dispersive diffraction. J Mater Sci Lett 13:1232-1234

Shulpekov AM, Lepakova OK, Radishevskaya NI (2018) Phase - and structural formation in the TIO2-AL-C system in the SHS process. Chem Bull 1(1):4-11

Solovyov LA (2004) Full-profile refinement by derivative difference minimization. J Appl Crystallogr 37:743-749

Strokova VV, Botsman LN, Ogurtsova YN (2015) Impact of epicrystallization modifying on characteristics of cement rock and concrete. Int J Appl Eng Res 10(24):45169-45175

Open Access This chapter is licensed under the terms of the Creative Commons Attribution 4.0 International License (http://creativecommons.org/licenses/by/4.0/), which permits use, sharing, adaptation, distribution and reproduction in any medium or format, as long as you give appropriate credit to the original author(s) and the source, provide a link to the Creative Commons license and indicate if changes were made.

The images or other third party material in this chapter are included in the chapter's Creative Commons license, unless indicated otherwise in a credit line to the material. If material is not included in the chapter's Creative Commons license and your intended use is not permitted by statutory regulation or exceeds the permitted use, you will need to obtain permission directly from the copyright holder.

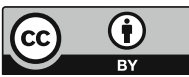

